\title{
AC 2010-1258: ENGINEERING DESIGN CASE STUDIES: EFFECTIVE AND SUSTAINABLE DEVELOPMENT METHODS
}

Oscar Nespoli, University of Waterloo

Steve Lambert, University of Waterloo 


\title{
Engineering Design Case Studies: Effective and Sustainable Development Methods
}

\begin{abstract}
Case studies and the case method of teaching and learning have demonstrated pedagogical benefits. Sustaining the effective and efficient development of cases requires strategies and methods that are proven and systematic.

Waterloo Cases in Design Engineering (WCDE) is a unique program to enhance design engineering education by converting student co-op work term reports into case studies and implementing them across all courses in the Faculty of Engineering curriculum. Cases have been implemented successfully, and show promise in addressing and demonstrating new Canadian Engineering Accreditation Board (CEAB) graduate attribute requirements. The case method also shows promise in integrating these required attributes by expressing real situations encountered in practice and allowing individual students and student teams to experience realistic challenges in a classroom setting.
\end{abstract}

In addition to developing cases from work term reports, cases have been developed from student capstone project experiences, Master of Engineering (MEng) design project experiences, and directly from the experiences of our industry partners. The development strategies and methods used to ensure effective and timely development of cases varies depending on the source used.

This paper describes the development methods used to successfully develop sustainable sources of engineering design case studies, and offers lessons-learned perspectives from our development and implementation experiences.

\section{Introduction}

Waterloo Cases in Design Engineering (WCDE) was established with the support of the Natural Science and Engineering Research Council (NSERC), General Motors of Canada Limited (GMCL) and the University of Waterloo (UW) to enhance the teaching and learning of engineering design in all courses across the entire Faculty of Engineering.

Case studies and specifically the case method of learning have demonstrated pedagogical benefits as proven mechanisms to capture real engineering experiences for use in a university environment [1]. Case studies continue to be used in engineering curricula, particularly as case histories featuring notable failures [2]. Case study programs have been established at several universities to date, but none have been as prevalent as programs that have been established at business schools, for example. We believe this can be addressed by ensuring that both the sources and development methods for the case studies be effective and sustainable.

As an exclusively co-op engineering school, UW engineering students generate over 4000 work term reports per year. This represents a large sustainable source of student engineering experience that can be used for the development of design case studies. This established linkage 
between university and industry is an ideal network to foster the flow of real world experience and for our students to benefit from that experience. This would better prepare them for engineering design work and professional practice in general.

Case studies provide rich context for an engineering problem or design situation. They offer opportunities to integrate theoretical knowledge gained by traditional lecture and tutorial teaching methods. Cases offer students opportunities to develop procedural knowledge and skills in applying and integrating theoretical concepts to the real situations described in the case studies. Cases also offer learning opportunities for problem finding, teamwork, project management, economics and communications skills. Case studies provide an opportunity for a natural integration of these key engineering skills, in addition to the scientific and engineering principles learned. An important advantage to the pervasive use of case studies and the case method of active learning is the ability to specifically address the new Canadian Engineering Accreditation Board (CEAB) graduate attribute requirements [3], that follow the ABET requirements relatively closely. Table 1 presents a list of these attributes. These attributes can all be addressed using case studies and the case method, either individually or in combination.

\begin{tabular}{|l|l|}
\hline & Criteria \\
\hline 1 & A knowledge base for engineering \\
\hline 2 & Problem analysis \\
\hline 3 & Investigation \\
\hline 4 & Design \\
\hline 5 & Use of engineering tools \\
\hline 6 & Individual and team work \\
\hline 7 & Communication skills \\
\hline 8 & Professionalism \\
\hline 9 & Impact of engineering on society and the environment \\
\hline 10 & Ethics and equity \\
\hline 11 & Economics and project management \\
\hline 12 & Life-long learning \\
\hline
\end{tabular}

Table 1: Canadian Engineering Accreditation Board (CEAB) graduate attributes [3]

However, without sustainable sources of real engineering experiences, and the methods to develop design case studies, it is difficult to establish and grow a program to provide the educational impact required. WCDE have developed a case development process and case study source development methods that are effective, sustainable and systematic. We describe these methods below.

\section{WCDE Case Development Methods}

The case study development method used at the WCDE consists of two (2) major phases:

i. $\quad$ Case study source material identification and development

ii. Case study development, release, implementation, distribution and retirement 
The case study development method is depicted in Figure 1, while the source identification and development methods are depicted in Figures 2 to 6 below. The case study development method is described first, and the source material development methods described thereafter.

Case sources used by WCDE are:

i. Co-op student experiences and work-term reports

ii. Capstone design project experiences and reports

iii. Master of Engineering (MEng) design project experiences and design case study reports

iv. Industry partner direct experiences and interaction with faculty

\section{Case Study Development Process}

The case study development process begins with the intent to develop decision by the case developer, student, faculty member and industry partner as contributing authors. Typically the case study source material has been collected and reviewed prior to this point, and the development team has been introduced. They have had time for preliminary discussions regarding the broad educational goals and promotional benefits to all stakeholders.

The case developer then develops a case plan document. The purpose of the case plan is to provide an outline of the case study in order to obtain provisional approval. Obtaining agreement at this stage reduces the risk of investing work in developing a full case and then not being able to obtain approvals from the stakeholders at a later time.

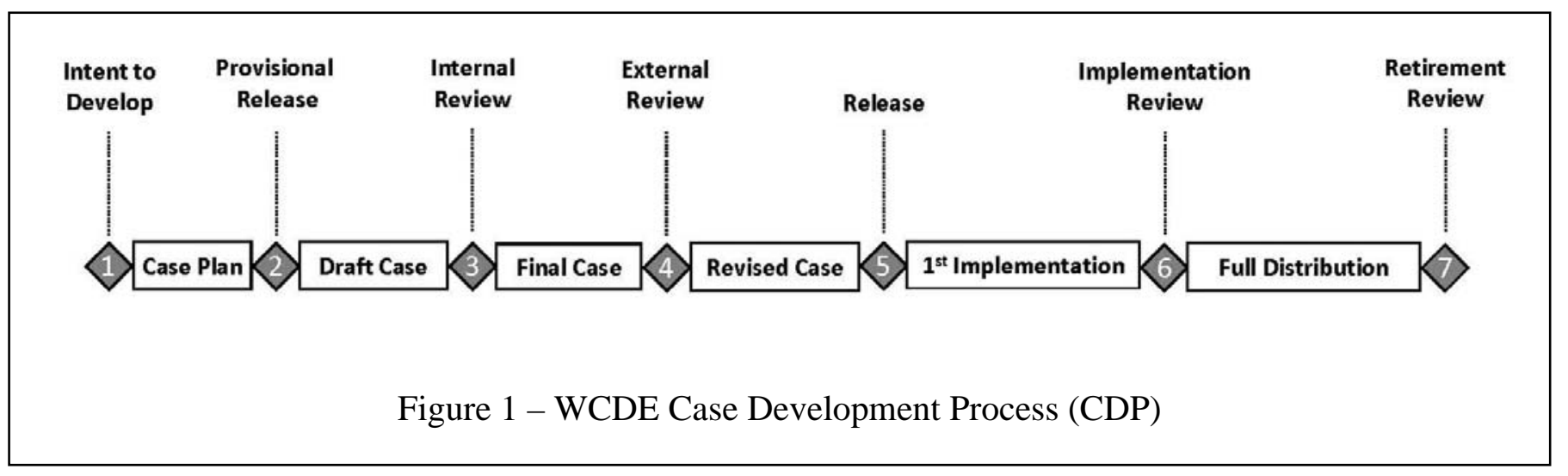

The case plan includes the following information:

- Case study title

- Contributing authors as they are to be listed

- Introduction with a figure (1 page)

- Expected learning outcomes (1 paragraph)

- Case outline using titles, subtitles and bulleted points (1/2 page)

- Additional data and exhibits (1 paragraph)

- Time plan (1 page)

- Copyright license model agreement (2 pages) 
- $\quad$ Case release form (1 page)

The case plan is generated using the same format as a released case, including footnote information and WCDE branding.

Once approvals have been given by the student, industry partner and faculty member, the case developer writes the first case draft. This is reviewed internally for pedagogical content and structure, technical content and applicability to the identified learning outcomes, and for editorial content. The authors then review the draft case, providing their comments. Once the comments are incorporated, the case is presented to the remaining stakeholders for release. A copyright license agreement is presented to all contributing authors for signing, and the case release form is presented to an authorized company representative along with the final case. The distribution level is selected by the company representative. They are given the option of use within the University of Waterloo only, or all institutions.

The case itself presents the business context and the engineering challenge. Separate modules, typically structured along the lines of the engineering design method, with needs assessment, conceptual design, preliminary design, detailed design, and implementation, present the chosen solution. Only the case itself is typically released to students. The modules are for the use of the professor in preparing assignments or projects based on the case. A draft teaching note is developed in order to recommend one or more implementation plans in collaboration with the lead faculty member. It is updated after the $1^{\text {st }}$ implementation, and published for professors use only prior to broader distribution beyond UW.

\section{Case Study Source Development}

The largest sustainable source of case study material is through the harvesting of work term reports generated by co-op students. UW engineering student must submit work term reports for academic credit. Over 4000 work term reports are submitted for academic credit each year.

Figure 2 shows how work term reports are obtained for case study conversion. At the beginning of each academic term (each term is 4 months long), students are made aware of their option to submit their work term reports to the WCDE for review. This is done through local promotion when they arrive on campus. Once the work term reports are collected, they are copied and reviewed for suitability. If one is selected, students will be notified and the work term report conversion assigned to a WCDE case developer. This is the most traditional and reliable method of obtaining a sustainable source of case study materials.

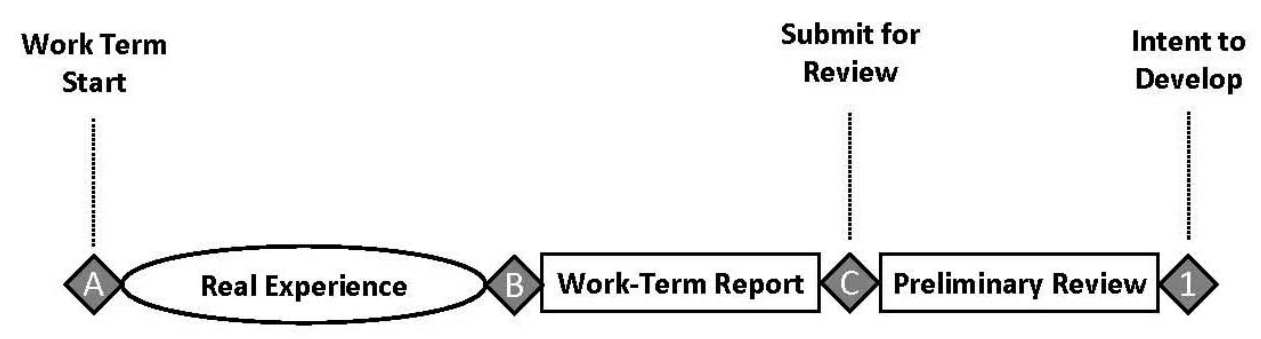

Figure 2 - Sustainable Case Source Development from Co-op Work Term Reports 
A variation of the above method is depicted in Figure 3 below. For selected opportunities, it may be advantageous to present an overview of the WCDE program to a specific industry partner. In this case, WCDE representatives would request a meeting with industry supervisors and co-op students that they have hired at the beginning of the co-op term. WCDE would facilitate a so-called seeding meeting, whereby WCDE would try to find a suitable topic for immediate curriculum needs that match the industry partner's requirement to do engineering work. If the student was interested in the proposal, then they would undertake the work and the development of a work term report, with the understanding that it would be submitted by them for possible conversion into a case study.

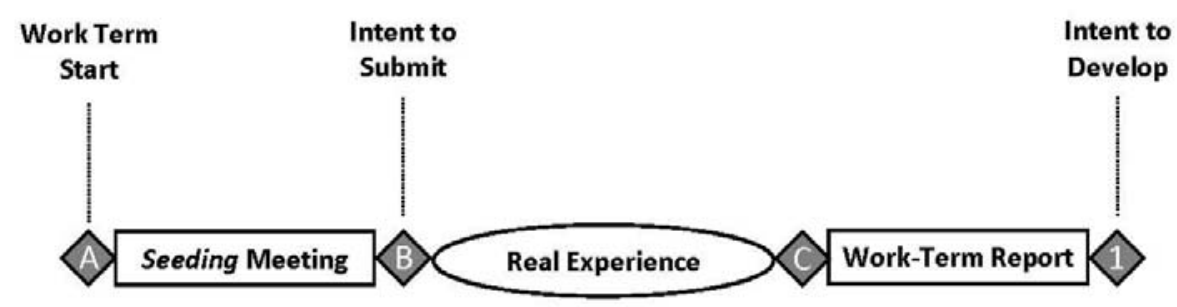

Figure 3 - Sustainable Case Study Source Development from Co-op Student Seeding

This approach has proven to be very efficient, since WCDE personnel can offer advice to the student during the term, and become educated about the topic prior to the start of the case development process. The student also benefits from this process, as it is often a challenge to identify a suitable work term report topic.

Another sustainable source of case study material is the $4^{\text {th }}$ year design project report, or the capstone design experience, shown in Figure 4. This source is available to all engineering universities, whether a co-op school or not.

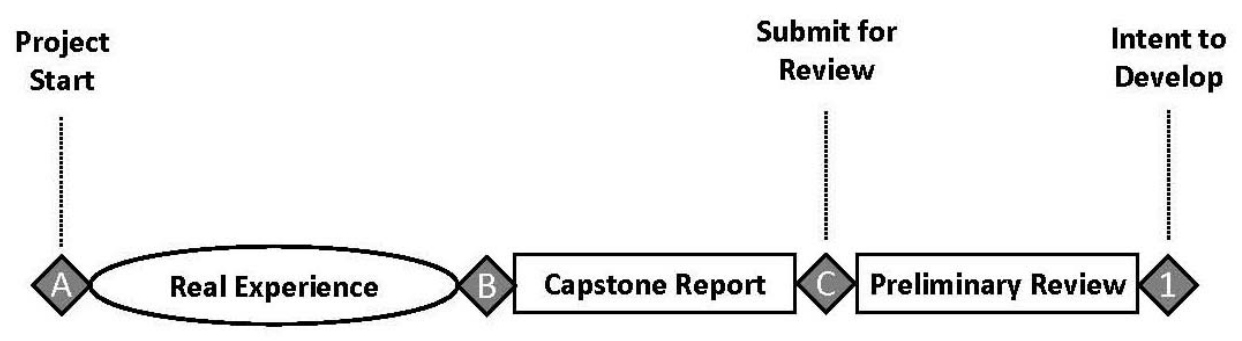

Figure 4 - Sustainable Case Study Source Development from Capstone Project Reports 
Students simply submit their reports to the WCDE for consideration. In some cases faculty advisors have recommended that students submit their reports for case study conversion.

Typically students are motivated to promote their design project as it is often a topic that they are excited about. Students have reported that they enjoy doing case studies that fellow students have designed as part of their $4^{\text {th }}$ year design project. Student engagement is an important factor in the design and implementation of case studies.

The Department of Mechanical and Mechatronics engineering offers a Master of Engineering, course-based program with a specialization in design. The Design Certificate is obtained after the student successfully completes three (3) design courses, including two (2) design project courses. Industry partners often sponsor design projects. Students submit a design case study instead of a traditional final report as part of their academic credit.

This is also a sustainable source of case study material, with the unique feature that the design case is already in the required form and structure (Figure 5). The follow-on case development process may proceed to final editing and release approvals. The available volume of design case studies is much lower than the co-op student work term reports, or the capstone design project reports, but they are typically very interesting and intensive design challenges, and appropriate for use in both the undergraduate and graduate curricula.

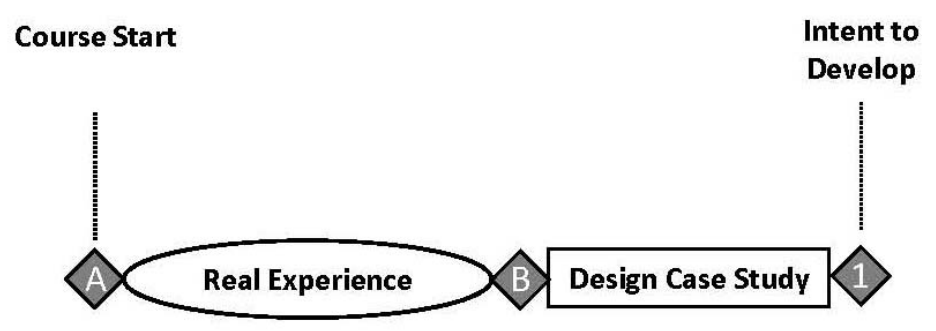

Figure 5 - Sustainable Case Study Source Development from Master of Engineering (MEng) Design Projects

Case studies can also be developed directly from the experiences of our industry partners (Figure 6). This is typically a source that is available through industry contacts of faculty, or after contact has been made through one of the case source development processes above.

Many practitioners are very willing to participate in developing a case study, including acting as guest lecturers to support the delivery in class. This is an actionable mechanism for industry to provide educational material they believe the curriculum and students could benefit from.

Typically this requires the most work of a case developer, however, it is a viable option especially for faculty, since they can develop a case that closely fits their course educational requirements. 


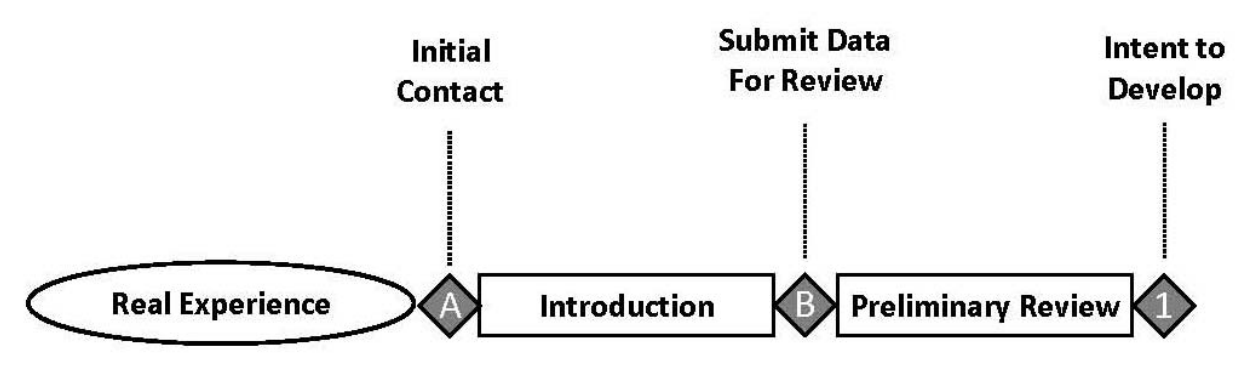

Figure 6 - Sustainable Case Study Source Development from Industry Practitioners

\section{Results and Discussion}

Case studies have been developed from all of the sources identified above.

A power supply design case study [4] and a case study featuring project management contingency planning with General Motors of Canada Limited (GMCL) [5] were developed directly from student co-op work term reports.

A case study examining the feasibility of a sand bath heater for chemical process design [6] was derived directly from a student work term report, where WCDE case developer met with the student and supervisor in a seeding meeting to agree on a work term report topic. This case develop activity was very efficient, since the student was offered advice in structuring the work term report during the work term by a case developer. This allowed for a smooth conversion transition into a useable case study.

A novel foot brace orthotic [7] and a custom designed cabinet press design [8] are case studies that were derived directly from $4^{\text {th }}$ year capstone design project reports. Both projects followed the engineering design process and produced useful artifacts. The cases were developed as socalled interrupted case studies, where several modules are given to students, one at a time, in order to emphasize the stages in the design process.

A case study featuring the design of a novel assistive device [9] was developed from a class project in the Master of Engineering (MEng) Design Certificate program. The case study featured need analysis and project planning in order to address challenging requirements for a local glass carving artist.

A heavy mining construction truck brake design case study [10] and a case study featuring the industrial and mechanical design of a novel pharmaceutical laboratory instrument [11] were developed directly from industry partner experiences. In both cases the industry partner felt a need to contribute material that they wanted to students to learn about, and that they felt was lacking in students' education. A case study that was developed directly from a Faculty 
member's experience in improving the heating and insulation in his home [12] was used in both first year and upper year courses to facilitate the understanding of heat transfer and the design process.

This portfolio of case studies demonstrates that the development method described can be used to effectively develop case studies from a variety of sources. While the development of case studies from work term reports are limited to co-op universities, all universities could use capstone design project reports or develop cases studies directly from industry. An important long-term objective of this program is to make some case studies available to other educational institutions.

Our initial experience with the development of case studies from work term reports and $4^{\text {th }}$ year projects has been published previously $[13,14]$ and is updated here based on our additional experiences.

We have learned that students very much appreciate design case studies, believe that they help them understand course concepts, that they provide relevance to the material presented in class, and that the group and classroom discussions further help them to understand the course concepts. We believe this is an ideal opportunity for the student group to develop teamwork skills as well $[15,16]$.

In [15] we reported results of a three (3) course implementation of a case study developed from a $4^{\text {th }}$ year capstone project report. As shown in Figures 7 and 8, students reported that the case was engaging and that it helped them understand the specific course topics (i.e. engineering design and synthesis). These results have been also supported in a recent implementation of a case study derived directly from industry in a smaller $4^{\text {th }}$ year mechanical design class [17]. The results of a student survey were similar and are presented in Figures 9 and 10.

The important lessons-learned in the sourcing and development of case studies for a sustainable engineering case study program includes:

i. $\quad$ Educating all participants in the case method of teaching and learning

ii. Ensuring a strong commitment exists from student, faculty, industry partner and case developer to develop and publish the case study after provisional release is granted

iii. Identifying learning outcomes that match curriculum needs, and expressing the learning outcomes to ensure assessment of the learning is feasible at the completion of the case study

iv. Identifying survey questions that are meaningful for improving the quality and appropriateness of the case studies in fostering active learning and therefore understanding and meaning 


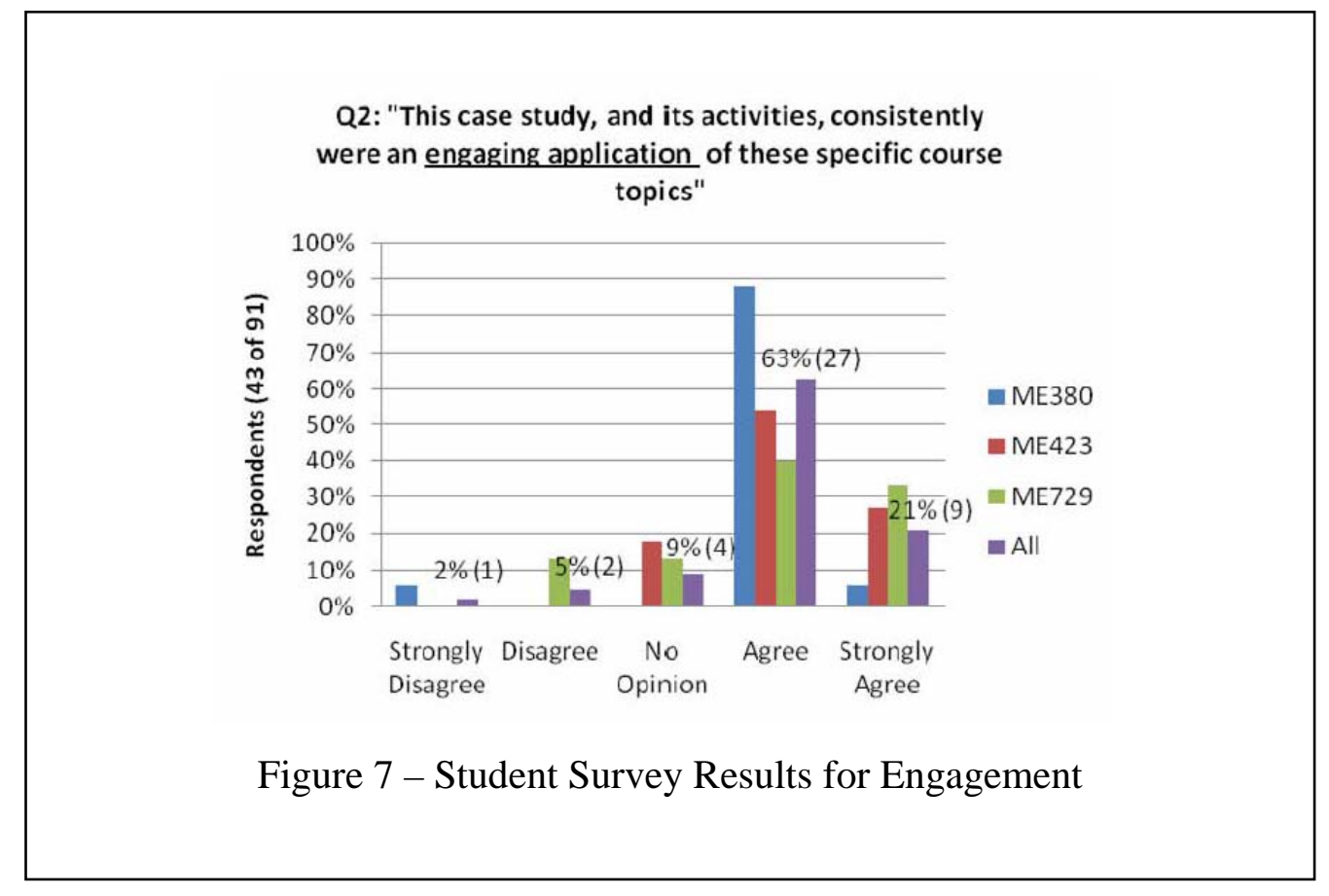

Q5: "This case study, and its activities, consistently helped me understand these specific course topics"

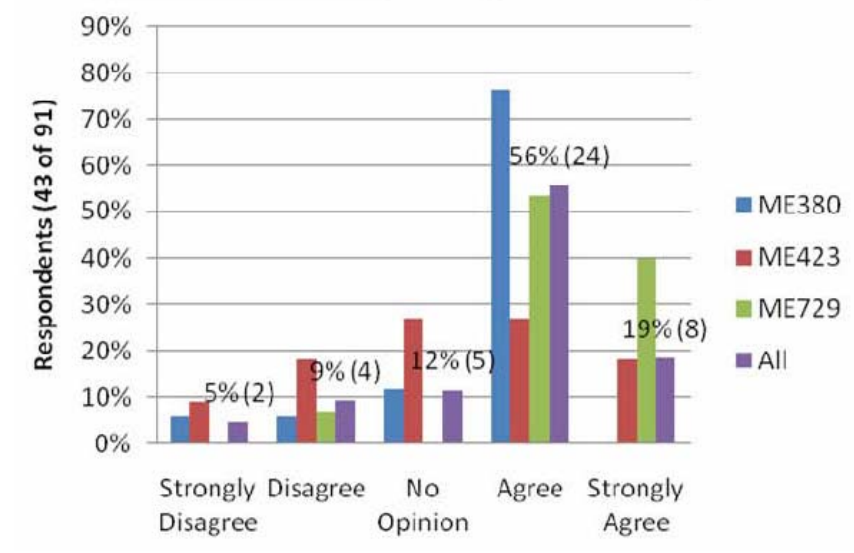

Figure 8 - Student Survey Results for Understanding 
Q2: This case study was an engaging application of these specific course topics

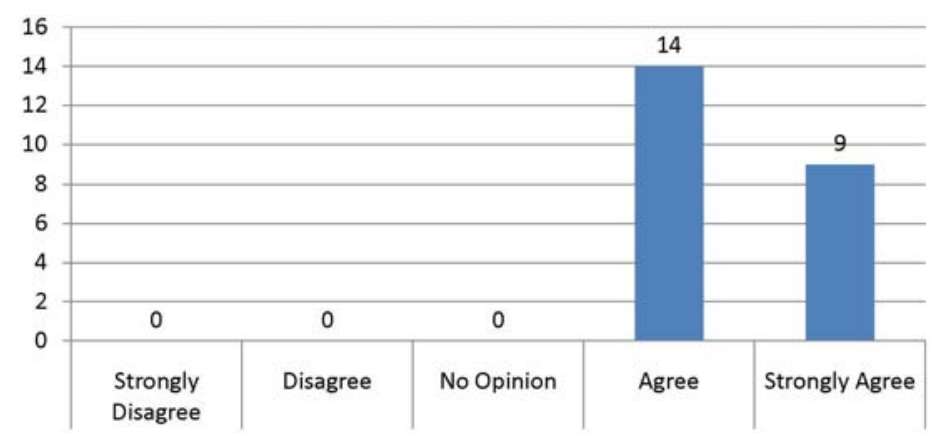

Figure 9 - Student Survey Results for Engagement

Q4: This case study helped me understand these specific course topics

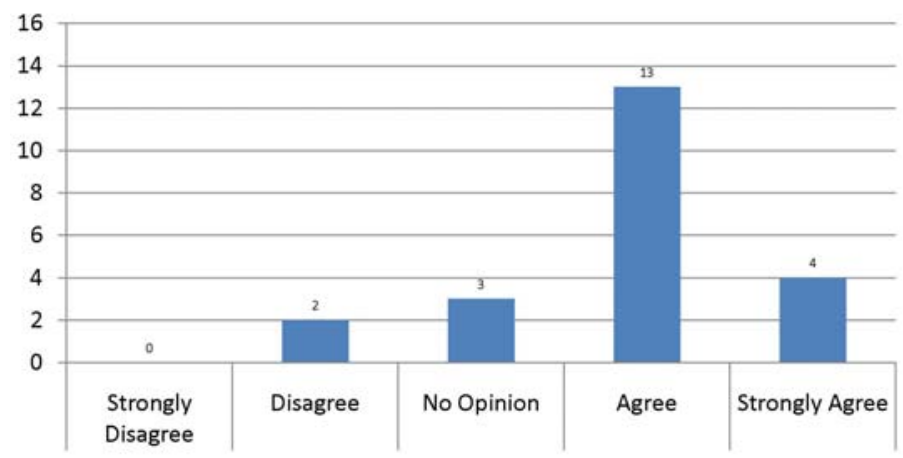

Figure 10 - Student Survey Results for Understanding 


\section{Summary}

The methods we have developed and presented have been found to be a reliable, systematic and effective means to produce engineering design case studies for our curriculum. The sustainability and effectiveness of these methods will allow the WCDE program to meet the daunting challenges of cultural change with students, faculty and industry in learning and teaching with case studies over time. Additional refinements to these methods and continued perseverance will allow WCDE to provide a sustainable volume of readily available case studies that both UW and the educational community at large. These can be used to enhance the learning of engineering design, as well as addressing and demonstrating CEAB graduate attribute requirements or ABET educational outcomes for engineering curricula, for both continuous improvement and accreditation purposes.

\section{References}

1. L.G. Richards, M. Gorman, W.T. Scherer, and R.D. Landel, 1995. "Promoting Active Learning with Cases and Instructional Modules”, Journal of Engineering Education. pp. 375-381.

2. H. Petroski, Design Paradigms: Case Histories of Error and Judgment in Engineering, Cambridge University Press, 1994.

3. Canadian Engineering Accreditation Board, “Accreditation Criteria and Procedures 2008”, text-only version, September 2008, available from www.engineerscanada.ca, accessed January 2009.

4. B. Laurence and C. Walsh, “Nuvation Research Corporation Power Supply Characterization System”, WCDE00076, Waterloo Cases in Design Engineering (WCDE), February 2010.

5. N. Mathew, R. Szymczyk and O. Nespoli, “GMCL Contingency Planning for TPMS”, WCDE-00027, Waterloo Cases in Design Engineering, December 2009.

6. F. K. Cheuk, A. Hagedorn and O. Nespoli, “Zeton Inc.: Sand Bath Heater Feasibility Study”, WCDE-00028, Waterloo Cases in Design Engineering, June 2009.

7. D. Bishop and O. Nespoli, "Foot Brace Design for Long Distance Running”, WCDE-00023, Waterloo Cases in Design Engineering, March 2008.

8. J. Burger, P. Burger and O. Nespoli, “EPB Custom Cabinets”, WCDE-00060, Waterloo Cases in Design Engineering, March 2009.

9. T. MacDonald, W. Chan and O. Nespoli, “Glass Carving Assistive Device - Project Planning and Management”, WCDE-00070-02, Waterloo Cases in Design Engineering, December 2009.

10. H. Templeman, R. Spencer and O. Nespoli, "Hitachi Truck Brake Design”, WCDE-00058, Waterloo Cases in Design Engineering, July 2009.

11. A. Liederman, Carla Ring-Herron, Lahav Gil, Ray Cracauer and Oscar Nespoli, “dotLab® System Industrial Design”, WCDE-00073, Waterloo Cases in Design Engineering, December 2009.

12. S. Lambert, “Elora Home Heating”, WCDE-00022, Waterloo Cases in Design Engineering, May 2008.

13. O.G. Nespoli, A. Hagedorn, C. Campbell and S. Lambert, “A Comparison of Business Case and Engineering Design Case Structures”, Proceedings of the Canadian Design Engineering Network (CDEN) Conference, 2008. 
14. O.G. Nespoli, A. Hagedorn, C. Campbell and S. Lambert, "Creating Engineering Design Cases from Student Work Term and Design Project Reports”, Proceedings of the Canadian Design Engineering Network (CDEN) Conference, 2008.

15. O.G Nespoli, W. Owen and S. Lambert, "Engineering Case Study Implementation: Observations, Results and Perspectives”, American Society of Engineering Education Conference, Austin, Tx. 2009.

16. O.G. Nespoli, W. Owen and S. Lambert, "Using Case Studies to Promote Group Learning and Teamwork Skills”, Proceedings of the Canadian Design Engineering Network (CDEN) Conference, 2009.

17. S. Lambert and O. Nespoli, "Building a Foundation for Multidisciplinary Design Using Case Studies", Transforming Engineering Education: Creating Interdisciplinary Skills for Complex Global Environments”, IEEE, Dublin, Ireland, April 2010 (Accepted). 